\title{
Significantly Reducing Blood Loss Using Intra- muscular Injection of Tranexamic Acid during Total Knee Arthroplasty
}

Yu-Kuan Lin

Taipei Veterans General Hospital

Shang-Wen Tsai

Taipei Veterans General Hospital

Po-Kuei Wu

Taipei Veterans General Hospital

Chao-Ming Chen

Taipei Veterans General Hospital

Jesse Chieh-Szu Yang

Taipei Veterans General Hospital

Cheng Fong Chen ( $\nabla$ cfchenjoa@gmail.com )

Taipei Veterans General Hospital https://orcid.org/0000-0003-3572-8053

\section{Wei-Ming Chen}

Taipei Veterans General Hospital

\section{Research article}

Keywords: intra-muscular injection, tranexamic acid, total knee arthroplasty, blood loss, complication

Posted Date: October 5th, 2020

DOl: https://doi.org/10.21203/rs.3.rs-53278/v1

License: (a) This work is licensed under a Creative Commons Attribution 4.0 International License.

Read Full License

Version of Record: A version of this preprint was published at BMC Musculoskeletal Disorders on August

17th, 2021. See the published version at https://doi.org/10.1186/s12891-021-04591-0. 


\section{Abstract \\ Background}

Administration of an intra-muscular injection (IMI) of tranexamic acid (TXA) had been demonstrated to be effective in reducing both blood loss and the transfusion rate during total knee arthroplasty (TKA). However, few studies have reported on the efficiency of IMI of TXA. We studied the efficiency of IMI of TXA to reduce blood loss during TKA.

\section{Methods}

In this prospective study, 50 patients undergoing primary simultaneous bilateral TKA were enrolled. The right knee received a IMI of $1 \mathrm{~g}$ of TXA (Group I), and the left knee received an intra-articular injection (IAI) of $1 \mathrm{~g}$ of TXA (Group II). The clinical outcome measures were a change in hemoglobin levels, blood loss from Hemovac, and number of allogeneic blood units.

\section{Results}

Compared with Group II, the decrease in blood loss from Hemovac was significantly less for Group I $(460.1 \pm 36.79$ vs. $576.0 \pm 34.01, P<0.001)$, and no significant difference in surgical times was observed.

\section{Conclusions}

IMI of TXA can significantly reduce blood loss than IAI of TXA during TKA without increased complications such as surgical site infection, poor wound healing, skin necrosis, pulmonary embolism, and deep vein thrombosis.

\section{Background}

Knee osteoarthritis is an increasingly common disease that causes knee pain, limited range of motion, and reduced quality of life and ability to conduct activities of daily living. Total knee arthroplasty (TKA) is a reliable surgical method for treating these signs and symptoms. However, postoperative blood loss is a major risk during TKA. Studies conducted between the years 2000 and 2009 have reported blood loss of $1000-1790 \mathrm{~mL}$ during unilateral TKA and an increase in the incidence of allogeneic blood transfusion [1-4]. More blood loss and higher incidences of complications such as anemia, weakness with delayed rehabilitation, and poor wound healing have previously been noted [5]. Although allogeneic blood transfusions are a safe and effective treatment for considerable postoperative bleeding, blood transfusions have potential risks, including the risks of immunological allergy, infection, and mortality; in addition, blood transfusions lengthen hospital stays and increase costs. Therefore, numerous approaches have been developed to reduce the amount of blood loss and the rate of blood transfusion 
such as minimally invasive surgery, the use of a tourniquet during surgery, and hypotension anesthesia. In addition, the use of intravenous and intra-articular tranexamic acid (TXA) has been reported to safely and effectively reduce the amount of blood loss and likelihood of blood transfusions in TKA [6-8].

Peri-articular injection (PAI) of multimodal drugs, which are directly applied into the soft tissue around the surgical site, is an efficient means of reducing postoperative pain, shortening hospital stays, and enabling patients to be rehabilitated earlier [9-12].

However, reports on the efficacy of intra-muscular injection (IMI) using a local-pain-control cocktail combined with TXA in TKA are few [13-15]. Therefore, in this study, we compared blood loss during bilateral TKA when one knee received intra-muscular TXA injection and the other knee received intraarticular TXA injection.

\section{Methods}

A total of 50 patients who underwent simultaneous bilateral TKA for advanced knee osteoarthritis from January to August 2017 were included in this prospective study. The inclusion criteria were $\geq 60$ years of age diagnosis of advanced knee osteoarthritis, and receipt of bilateral TKA. The exclusion criteria were a history of knee surgery, inflammatory arthritis, and osteoarthritis due to infection, unilateral TKA, renal failure and a bleeding or platelet disorder. Patient demographic data that were collected, such as age, sex, body mass index (BMI), and Charlson comorbidity index [16].

Group I comprised right knees that received IMI of TXA $(1 \mathrm{~g} / 10 \mathrm{~mL})$. Group II comprised left knees that received IAI of TXA $(1 \mathrm{~g} / 10 \mathrm{~mL})$.

The surgical procedures were performed by one single experienced joint surgeon. During surgery, the patients were in the supine position and under spinal anesthesia. Before skin incision, the tourniquet was inflated until the pressure to $280 \mathrm{mmHg}$. It was then deflated after the IMI or IAI of TXA. A curved skin incision was made via a midvastus approach. The prosthesis used was the cement-fixed NexGen posterior-stabilized knee system (Zimmer Biomet). The sites of IMI were the rectus femoris, vastus medialis, patella tendon, pes anserinus, and posterior capsule. Surgical drains were inserted into the joints and clumped, then opened 1 hour after surgery, suctioned using full-negative pressure, and removed 48 hours after surgery. Standard wound closure was performed, and sterile dressing was applied. The procedures were performed on the right knee first then on the left knee.

The postoperative regimes were the same for all patients except for those with a BMI greater than $30 \mathrm{~kg} / \mathrm{m}^{2}$. These patients received an injection of low-molecular-weight heparin at 2000 internatinal units daily for 3 days to prevent thromboembolism. Hemoglobin $(\mathrm{Hb})$ level was rechecked on the first day after the operation. The criteria for blood transfusion were $\mathrm{Hb}<8 \mathrm{mg} / \mathrm{dL}$ and a decrease in the $\mathrm{Hb}$ level of more than $3.0 \mathrm{mg} / \mathrm{dL}$ if the patient had intolerable symptoms or organ dysfunction due to anemia. All patients underwent mobilization on the first postoperative day and were discharged 5 days after surgery. 
The clinical outcomes were the Hemovac volume of each knee, $\mathrm{Hb}$ level change, and transfusion rate.

All analyses were performed using IBM SPSS Statistics 22.0 (IBM, Armonk, NY, USA). The characteristics of thw two groups were analyzed using one-way analysis of variance (age, BMI, ASA, Charlson comorbidity index, pre- and postoperative $\mathrm{Hb}$ level, preoperative platelets, surgery time, and total $\mathrm{Hb}$ reduction) and the chi-squared test (sex and transfusion rate). The numbers of units was assessed using the Kruskal-Wallis test. $P<0.05$ was considered statistically significant.

This clinical study was approved by the institutional review board at our hospital, Taipei

Veterans General Hospital. (IRB number: 2018-09-004CC)

\section{Results}

During the period from January to August 2017, 50 patients who met the inclusion criteria were enrolled in Group I for simultaneous bilateral TKA. The right knees (Group I) received IMI of TXA $(1 \mathrm{~g} / 10 \mathrm{~mL})$, whereas the left knees (Group II) received IAI of TXA $(1 \mathrm{~g} / 10 \mathrm{~mL})$.

The demographic data and preoperative blood test results of the patients, and a comparison of the results between Group I and Group II are presented in Table 1. 
Table 1

Patient-Demographic and Pre- and Post-operative data

\begin{tabular}{|c|c|c|c|}
\hline Number & 50 & & \\
\hline Age (years) & $70.46 \pm 1.26$ & & \\
\hline \multicolumn{4}{|l|}{ Gender } \\
\hline Male/Female & $\begin{array}{l}36.0 \%(18 / 50) / 64.0 \% \\
(32 / 50)\end{array}$ & & \\
\hline BMI $\left(\mathrm{kg} / \mathrm{cm}^{2}\right)$ & $27.65 \pm 0.46$ & & \\
\hline ASA & $2.44 \pm 0.07$ & & \\
\hline Charlson index score & $1.30 \pm 0.15$ & & \\
\hline $\mathrm{Hb}$ preoperative (mg/dL) & $12.77 \pm 0.24$ & & \\
\hline $\begin{array}{l}\text { PLT count preoperative } \\
\text { (count } \times 10^{3} / \mathrm{mm}^{3} \text { ) }\end{array}$ & $217.6 \pm 7.89$ & & \\
\hline $\mathrm{Hb}$ postoperative $(\mathrm{mg} / \mathrm{dL})$ & $10.51 \pm 0.23$ & & \\
\hline $\mathrm{Hb}$ change (mg/dL) & $-2.26 \pm 0.21$ & & \\
\hline \multirow{2}{*}{$\begin{array}{l}\text { Transfusion rate } \\
\text { (number/\%) }\end{array}$} & $8(16 \%)$ & & \\
\hline & $\begin{array}{l}\text { Peri-articular injection } \\
\text { (Group I) }\end{array}$ & $\begin{array}{l}\text { Intra-articular injection } \\
\text { (Group II) }\end{array}$ & $\begin{array}{l}P \\
\text { value }\end{array}$ \\
\hline Number & 50 & 50 & \\
\hline Surgery time & $33.96 \pm 0.73$ & $34.9 \pm 0.83$ & 0.065 \\
\hline Hemovac volume (ml) & $460.1 \pm 36.79$ & $576.0 \pm 34.01$ & $\begin{array}{l}< \\
0.001\end{array}$ \\
\hline
\end{tabular}

In Group I, the mean surgical time was $33.96 \pm 0.73$ minutes and the mean Hemovac volume was $460.1 \pm$ $36.79 \mathrm{~mL}$. In Group II, these values were $34.9 \pm 0.83$ minutes and $576.0 \pm 34.01 \mathrm{~mL}$, respectively..

Comparing Group I and Group II, the Hemovac volume was significantly lower in Group I $(P<0.001)$. The mean surgical times of the two groups did not significantly differ $(P=0.065)$.

The $\mathrm{Hb}$ level change of the patients was $-2.26 \pm 0.21 \mathrm{mg} / \mathrm{dL}$ and the transfusion rate was $16 \%(8 / 50)$. No patients had major or minor complications such as deep vein thrombosis, pulmonary embolism, surgical site infection, poor wound healing, and skin necrosis.

\section{Discussions}


According to reports, IAI of TXA results in significant reductions of blood loss, blood loss via the surgical drain, and $\mathrm{Hb}$ decrease $[2,8,17-19]$. Seo et al. reported that the transfusion frequencies after placebo, intravenous injection, and IAI of TXA were $94 \%, 34 \%$, and $20 \%$, respectively, and that these rated significantly differed between the intravenous injection and IAI of TXA groups. [17].

The blood loss noted after TKA was bone oozing and soft-tissue oozing. previously cement was placed between the bone-cutting site and implant component to reduce bone oozing, and IAI of TXA was employed to reduce blood oozing after synovectomy. However, muscle oozing was not effectively managed using this approach, and the studies on IMI of TXA in unilateral TKA are limited [13-15]. Mao et al. demonstrated that IMI and IAI of TXA efficiently at reducing blood loss during TKA compared with a control group; but the difference between IMI and IAI was nonsignificant [13]. Pinsornsak et al. reported that the antibleeding effects of intramuscular injected and intravenous injected TXA were similar [14]. Yozawa et al. reported that compared with placebo treatment, IMI of TXA was efficient at decreasing blood loss and drops in $\mathrm{Hb}$ and hematocrit [15].

In our study, IMI of TXA was more efficient at reducing blood loss in simultaneous bilateral TKA than IAI of TXA. Comparing Groups I and II, the Hemovac volumes of the IMI group (Group I) were significantly lower than those of IAI group (Group II) $(460.1 \pm 36.79 \mathrm{~mL}$ vs. $576.0 \pm 34.01 \mathrm{~mL}, P<0.001)$. The blood transfusion rate was $16 \%$ in our study, lower than that in the study of Seo et al. on unilateral TKA $(20 \%)$ [17].

Consequently, we conclude that IMI of TXA is effective at reducing blood loss and the blood transfusion rate in simultaneous bilateral TKA and that the pain-control cocktail plus TXA is safe for patients, not resulting in skin infections, poor healing, or necrosis.

Our study had two limitations. First, coagulation ability may influence their amount of blood loss during a procedure. All patients in our study received right TKA first, followed by left TKA. Second, the optimal dose of TXA was not clarified; more prospective-randomized studies are required to determine the most efficient TXA dose.

\section{Conclusions}

IMI of TXA can significantly reduce blood loss than IAI of TXA during TKA without causing deep vein thrombosis, pulmonary embolism, or skin problems.

\section{Abbreviations}

\section{IMI}

intra-muscular injection

TXA

tranexamic acid

TKA 
total knee arthroplasty

IAI

intra-articular injection

BMI

body mass index

ASA

American Society of Anesthesiologists

$\mathrm{Hb}$

hemoglobin

Plt

platelet

\section{Declarations}

\section{Ethics approval and consent to participate:}

The consent statement was not required due to it was a retrospective study which had been approved by the institutional review board at our hospital, Taipei Veterans General Hospital. (IRB number: 2018-09004CC).

\section{Consent for publication:}

Not applicable

\section{Availability of data and materials:}

The datasets analysed during the current study are not publicly available due to the data and materials were accessed from the case system of our department. They are available from the corresponding author on reasonable request.

\section{Competing interests:}

The authors declare that they have no competing interests.

\section{Funding}

This research did not receive any specific grant from funding agencies in the public, commercial, or notfor-profit sectors.

\section{Authors contributions}


C.-F. C. and W.-M. C. designed the work. Y.-K. L. drafted the work and P.-K. W. substantively revised it. S.-W. T., C.-M. C., J. CS Y., and Y.-K. L. also acquisition the data and analyzed them. All authors read and approved the final manuscript.

\section{Acknowledgements:}

I sincerely thank Dr. Szu-Ching Lee for providing technical help and writing assistance.

\section{References}

1. Bong MR, Patel V, Chang E, Issack PS, Hebert R, Di Cesare PE. Risks associated with blood transfusion after total knee arthroplasty. J Arthroplasty. 2004;19: 281-287, Apr, 2004.

2. Wong J, Abrishami A, El Beheiry $\mathrm{H}$, et al. Topical application of tranexamic acid reduces postoperative blood loss in total knee arthroplasty: a randomized, controlled trial. J Bone Joint Surg Am. 2010;92:2503-13. Nov 3, 2010.

3. Park JH, Rasouli MR, Mortazavi SM, et al. Predictors of perioperative blood loss in total joint arthroplasty. J Bone Joint Surg Am. 2013;95:1777-83. Oct 2, 2013.

4. Yoshihara $\mathrm{H}$, Yoneoka D. National trends in the utilization of blood transfusions in total hip and knee arthroplasty. J Arthroplasty. 2014;29: 1932-1937, Oct, 2014.

5. Vamvakas EC, Blajchman MA. Transfusion-related mortality: the ongoing risks of allogeneic blood transfusion and the available strategies for their prevention. Blood. 2009;113:3406-17. Apr 9, 2009.

6. Tzatzairis TK, Drosos GI, Kotsios SE, Ververidis AN, Voqiatzaki TD, Kazakos KI. Intravenous vs topic tranexamic acid in total knee arthroplasty without tourniquet application: a randomized controlled study. J Arthroplasty. 2016;31:2465-70. Nov, 2016.

7. Alshryda S, Sukeik M, Sarda P, Blenkinsopp J. Haddad FS, Mason JM. A systematic review and metaanalysis of the topical administration of tranexamic acid in total hip and knee replacement. Bone Joint J. 2014;96: 1005-1015, Aug, 2014.

8. Kim TK, Chang CB, Koh IJ. Practical issues for the use of tranexamic acid in total knee arthroplasty: a systematic review. Knee Surg Sports Traumatol Arthrosc. 2014;22: 1849-1858, Aug, 2014.

9. DeClaire JH, Aiello PM, Warritay OK, Freeman DC. Effectiveness of bupivacaine liposome injectable suspension for postoperative pain control in total knee arthroplasty: a prospective randomized, double blind, controlled study. J Arthroplasty. 2017;32: 268-271, Sep, 2017.

10. Jiang J, Teng T, Fan Z, Khan MS, Cui Z, Xia Y. The efficacy of periarticular multimodal drug injection for postoperative pain management in total knee or hip arthroplasty. J Arthroplasty. 2013;28: 18821887, Dec, 2013.

11. Peters CL, Shirley B, Erickson J. The effect of a new multimodal perioperative anesthetic regimen on postoperative pain, side effects, rehabilitation, and length of hospital stay after total joint arthroplasty. J Arthroplasty. 2006;21: 132-138, Sep, 2016. 
12. Kerr DR, Kohan L. Local infiltration analgesia: a technique for the control of acute postoperative pain following knee and hip surgery: a case study of 325 patients. Acta Orthop. 2008;79: 174-183, Apr, 2008.

13. Mao Z, Yue B, Wang Y, Yan M, Dai K. A comparative, retrospective study of peri-articular and intraarticular injection of tranexamic acid for the management of postoperative blood loss after total knee arthroplasty. BMC Musculoskelet Disord. 2016;17:438-45. Oct 19, 2016.

14. Pinsornsak P, Rojanavijitkul Chumchuen S. Peri-articular tranexamic acid injection in total knee arthroplasty: a randomized controlled trial. BMC Musculoskelet Disord. 2016;17:313-8. Jul 26, 2016.

15. Yozawa S, Ogawa H, Matsumoto K, Akiyama H. Periartiruclar injection of tranexamic acid reduces blood loss and the necessity for allogeneic transfusion after total knee arthroplasty using autologous transfusion: a retrospective observational study. J Arthroplasty. 2018;33: 86-89, Jan, 2018.

16. Charlson ME, Pompei P, Ales KL, MacKenzie CR. A new method of classifying prognostic comorbidity in longitudinal studies: development and validation. J Chronic Dis. 1987;40:373-83.

17. Seo JG, Moon YW, Park SH, Kim SM, Ko KR. The comparative efficacies of intra-articular and IV tranexamic acid for reducing blood loss during total knee arthroplasty. Knee Surg Sports Traumatol Arthrosc. 2013;21: 1869-1874, Aug, 2013.

18. McMonnell JS, Shewale S, Munro NA, Shah K, Deakin AH, Kinninmonth AW. Reducing blood loss in primary knee arthroplasty: a prospective randomised controlled trial of tranexamic acid and fibrin spray. Knee. 2012;19: 295-298, Aug, 2012.

19. Onodera T, Majima T, Sawaguchi N, Kasahara Y, Ishqaki T, Minami A. Risk of deep venous thrombosis in drain clamping with tranexamic acid and carbazochrome sodium sulfonate hydrate in total knee arthroplasty. J Arthroplasty. 2012;27: 105-108, Jan, 2012. 